\title{
Psychosocial Issues in Pediatric Inflammatory Bowel Disease: A Clinical Report of the North American Society for Pediatric Gastroenterology, Hepatology and Nutrition
}

\author{
Laura M. Mackner, Ph.D. ${ }^{1}$, Rachel Neff Greenley, Ph.D. ${ }^{2}$, Eva Szigethy, M.D., Ph.D. ${ }^{3}$, \\ Michele Herzer, Ph.D. ${ }^{4}$, Kate Deer, M.A. ${ }^{5}$, and Kevin A. Hommel, Ph.D. ${ }^{6}$ \\ ${ }^{1}$ Center for Biobehavioral Health, Nationwide Children's Hospital, Columbus, $\mathrm{OH}$ \\ ${ }^{2}$ Department of Psychology, Rosalind Franklin University of Medicine and Science, North \\ Chicago, IL \\ ${ }^{3}$ Division of Pediatric Gastroenterology, University of Pittsburgh, Pittsburgh, PA \\ ${ }^{4}$ Division of Developmental \& Behavioral Sciences/Division of Gastroenterology, Children's Mercy \\ Hospitals and Clinics, Kansas City, MO \\ 5 University of Hartford, Hartford, CT \\ ${ }^{6}$ Division of Behavioral Medicine and Clinical Psychology, Cincinnati Children's Hospital Medical \\ Center, Cincinnati, $\mathrm{OH}$
}

\begin{abstract}
Pediatric inflammatory bowel disease (IBD) can affect many areas of psychosocial functioning, and comprehensive medical care includes consideration of psychosocial issues as well as disease factors. The purpose of this clinical report is to review research on psychosocial functioning in pediatric IBD and to provide recommendations for care providers in the areas of psychopathology, health related quality of life and social, family and school functioning. Youth with IBD are at increased risk for difficulty in all areas reviewed, and many psychosocial factors are associated with disease activity, which highlights the importance of monitoring psychosocial functioning as part of clinical care. Several interventions have empirical support or show promise for addressing psychosocial difficulty, and recommendations for monitoring and treating these issues are provided.
\end{abstract}

\section{Keywords}

Psychosocial functioning; psychopathology; health related quality of life; social functioning; family functioning; school functioning

\section{Introduction}

Late childhood and adolescence are times of emotional, cognitive and social transition and also correspond to the peak age of onset of pediatric inflammatory bowel disease (IBD). As such, a diagnosis of chronic illness such as IBD can have a challenging impact with a range

Correspondence concerning this article should be addressed to Laura M. Mackner, Center for Biobehavioral Health, Nationwide Children's Hospital, 700 Children's Drive, Columbus, OH 43205. 614-722-4716. 614-722-3544 (fax).

Laura.Mackner@nationwidechildrens.org.

There are no conflicts of interest for any of the authors. 
of psychosocial adjustment problems. In many youth diagnosed with IBD, appropriate developmental milestones and normal functional growth is achieved by early adulthood. However, a child's overall adjustment may ultimately vary based on factors such as IBD course (e.g., chronic non-remitting versus remission) and treatment (e.g. high dose steroids, surgery), and longer term symptoms (e.g., growth and pubertal delay) may play a role. In addition to disease factors, brain maturation of emotional regulation, cognitive capacity, and behavioral impulse control across development can also influence the child's coping style and adjustment to illness. In general, children developing a chronic illness at a younger age are better able to incorporate the illness as part of their self-concept. In adolescents, when self-identity is in flux, dealing with an illness such as IBD can be particularly challenging. Both children and adolescents may feel embarrassment associated with fecal incontinence, poor body image due to steroid-induced weight gain, or social anxiety due to school absences and related loss of social learning opportunities. Of course in addition to age, factors such as family and social support, degree of disruption of the child's usual activities, and degree of stress, both early life and ongoing life stressors, may influence how children will react to having IBD. It is imperative for pediatric providers to pay attention to such psychosocial factors in evaluating how a child is coping with IBD.

The purpose of this clinical report is to review research in several areas of psychosocial functioning relevant to pediatric IBD and to provide recommendations for care providers (see Table 1). The psychosocial issues of psychopathology, health related quality of life and social, family and school functioning will be addressed. These psychosocial domains are interrelated but distinct constructs, so this report will address each separately and refer to other sections as needed. While the psychosocial topic of adherence/self-management is important, it warrants its own report to fully cover the research and recommendations in that area, so it will not be reviewed in this report.

\section{Psychopathology}

\section{Overview}

Major depression consists of either sadness or loss of interest or pleasure in activities for at least a 2 week period in addition to at least 5 of the following symptoms: changes in sleeping or eating habits with changes in weight and energy level (in excess or reduced when compared to usual habits); psychomotor agitation or retardation; feelings of worthlessness and guilt; trouble thinking or paying attention; recurrent thoughts of death; and suicidal ideation, plans, or attempts (see Table 2 for MESSAGE acronym for depression symptom assessment). In children, sad mood may manifest as labile mood, irritability, low frustration tolerance and frequent somatic complaints(1). In addition to meeting symptom criteria, a depressive diagnosis is also accompanied by impaired functioning compared to the child's usual baseline. Anxiety disorders represent a spectrum of disorders each with a unique set of identifying symptoms. In children and adolescents without IBD, separation anxiety, generalized anxiety (e.g., excessive worrying), obsessive compulsive (e.g., repetitive thoughts and or rituals) disorders as well as phobias are most common(2) and have also been reported in youth with $\operatorname{IBD}(3-5)$. Although post-traumatic stress disorder, an anxiety disorder triggered by an extreme traumatic event, is relatively uncommon in childhood, the impact of IBD particularly if there is chronic pain, ongoing procedures, and/ or surgery, may cause a milder form of stress disorder symptoms such as nightmares and increased autonomic response in a vulnerable subset of youth with chronic physical illness(6). In a small study of adolescents with IBD, IBD-specific anxiety was significantly associated with lower psychosocial functioning, worsened health related quality of life, and increased medical visits even after controlling for current IBD symptoms(5). 
Several studies have found adolescents with IBD to be more depressed than youth with other chronic diseases $(3,7)$ with rates as high as $25 \%(8)$. When a structured psychiatric interview for depression was administered, $96 \%$ of youth with elevated depressive severity scores (Children's Depression Inventory: CDI >10) met Diagnostic and Statistical Manual of Mental Disorders (DSM-IV)(9) criteria for either major or minor depression. In addition, depressed youth with IBD have been shown to be at higher risk for anxiety $(4,10,11)$ though the exact rates of disorder have been challenging to quantify. Most studies evaluating depression and anxiety have used continuous scales assessing severity and not DSM-IV diagnostic categorical analysis making true epidemiological estimates of incidence and prevalence challenging. In a meta-analytic review of psychosocial adjustment in 1167 youth with IBD, higher rates of depressive disorders and internalizing disorders (either depression or anxiety disorder) were documented(12). Interestingly, depressive or anxiety symptom severity in youth with IBD was not greater than those reported in healthy controls or other chronic diseases. These symptoms may not be elevated across the IBD population, but the patients who develop symptoms may be more likely to experience clinically elevated symptoms and increased risk for a disorder.

There are multiple studies both in pediatric and adult populations showing significant relationships of depression and/or anxiety with $\operatorname{IBD}$ disease activity $(8,13)$. One possible explanation for a positive association between IBD severity and depression is a direct effect of IBD-related inflammation, mediated in large part by pro-inflammatory cytokines. Depression in the context of visceral hyperalgesia (e.g., pain persisting during periods of inactive IBD) is also common(14). Exogenous steroids used to treat IBD have also been associated with depression(8) and this impact is thought to be mediated by the degree of sleep disturbance(15). There is also growing evidence supporting the relationship between sleep and inflammation, in fact, in 200 depressed children and adolescents with IBD, a clinically significant sleep disturbance was found in $65 \%$ of the sample(16).

In terms of anxiety, anti-oxidant damage to the autonomic nervous system (ANS) from chronic inflammation can be one potential mechanism for IBD-related anxiety. Psychosocial factors such as social isolation and other life stressors, early life adversity, parental conflict, and low socioeconomic class could also increase risk for internalizing disorders(1). For both depression and anxiety, it is also possible that a combination of genetic predisposition, environmental stressors, exaggerated negative reaction to having IBD, and IBD-induced changes in the brain and ANS could explain the elevated rates of psychopathology. It is, however, important to note that factors associated with anxiety and depression in youth with IBD have been found in studies with small samples and other methodological limitations, so the confirmation of models predicting psychopathology await larger scale studies.

Internalizing disorders are often associated with increased somatization, particularly involving abdominal pain in this population. Even in remission, IBD patients may still experience incapacitating abdominal pain that may also be accompanied by other functional gastrointestinal symptoms such as bloating, abdominal distention, diarrhea, urgency, loose stools, and constipation. In children with quiescent IBD, rectal sensory threshold for pain (RSTP) was significantly decreased in comparison with that of healthy controls(17). Etiological hypotheses about this persistent abdominal pain include visceral hypersensitivity or autonomic dysfunction due to damage from chronic inflammation, post-infectious sensitization of the enteric nervous system, dysfunctional motility, or complications due to surgery (e.g., strictures, obstruction). Changes in neurotransmitters localized in the enteric nervous system such as serotonin and catecholamines have also been implicated in IBDrelated dysfunction in gastrointestinal motility and nociception $(18,19)$. 


\section{Treatment of Psychopathology}

Psychosocial Treatments-Cognitive-behavioral therapy (CBT) is the psychotherapy with the most empirical evidence for efficacy in pediatric depression and anxiety(20). CBT is based on the idea that our thoughts, feelings, and behaviors are all inter-related, therefore, people can make positive changes in the way they feel by changing what they think or what they do. In adolescents with IBD, CBT with focus on illness perception has had a favorable impact on depression and anxiety symptoms in short-term studies that used medical treatment as the control group $(21,22)$ and these effects were maintained over a 12- month period(23). The more positive effects of psychotherapy in adolescents relative to adults may be due to their less-engrained behavioral tendencies and maladaptive coping strategies. In addition, other types of psychotherapy such as interpersonal therapy (e.g., exploring social roles) have been shown to have positive impact in medically healthy youth but have not been evaluated in pediatric IBD(24). Finally emerging evidence suggests that hypnotherapy may be useful among youth with $\operatorname{IBD}(25)$. While the use of pediatric hypnosis for pain, anxiety, and coping with a chronic illness is increasing, further empirical validation for efficacy is needed.

Pharmacotherapy-Although adjunctive psychotropic medications are routinely used in clinical care to treat anxiety, depression, and functional pain in patients with IBD, there are only small case series and case reports and not large-scale randomized trials supporting this practice. In physically healthy children and adolescents, several serotonin reuptake inhibitors (SSRI's) have FDA approval for the treatment of anxiety and depression(2). Fluoxetine has the most empirical support in double-blind placebo controlled trials for its efficacy for pediatric depression $(26,27)$ followed by sertraline $(28)$. One major trial supported the combination of fluoxetine and CBT over either alone in treating depression in the short-term(29). As with major depression, SSRI's are the first line medication for the treatment of anxiety disorders with fluvoxamine, sertraline, and fluoxetine showing the most support $(1,30)$. Venlafaxine ER has been shown to be efficacious in treating generalized anxiety disorder and social anxiety $(31,32)$. There is one small trial supporting the use of citalopram for functional abdominal pain in adolescents(33).

There have been no medication trials completed for anxiety and depression in youth with IBD. One open trial study showed benefit for adjunctive treatment of anxiety and depression with SSRI's or buproprion for patients who did not respond to CBT alone(4). Many other classes of psychotropic medications are available to treat anxiety, depression, and abdominal pain in pediatric cohorts but their endorsed use in youth with IBD awaits further study.

\section{Recommendations for Providers}

Regardless of the etiology of anxiety and depression, it is important for the treating physician to recognize warning signs and refer the patient for behavioral treatment as these have been shown to be effective in improving depression, even in the context of active IBD. It is important for the medical team to differentiate short-term distress that may be normal during flares or within a few months of initial diagnosis of IBD and which may be handled without referral in the context of an empathic provider-patient relationship from more severe symptoms (e.g., suicidality) or extended period of impaired functioning when referral may be warranted. Using screening tools such as MESSAGE or quality of life proxies (e.g., wellbeing item on the Pediatric Crohn's Disease Activity Index) at regular GI appointments or more frequently if the team senses extreme distress can also be a way of identifying at risk youth. While validated questionnaires like the Children's Depression Inventory(34) have also been useful, it is important to note that many such measures are not available in the public domain and must be purchased. 
In terms of treatment, cognitive behavioral therapy (CBT) has the most empirical support for the treatment of anxiety and depression in children and adolescents. The provision of CBT requires training and is best provided by a mental health professional with training in understanding the unique impact of pediatric chronic illness (e.g., psychologist, therapist, social worker, counselor). While serotonin re-uptake inhibitors and tricyclic antidepressants are commonly prescribed for comorbid psychopathology, abdominal pain, and sleep disturbance, there is little empirical support for their use. Thus careful documentation as well as frequent follow-up visits are recommended. It is important that pediatric providers define their threshold of comfort in prescribing psychotropic medications themselves versus referral to a psychiatrist. For patients who have failed a class of antidepressant, have severe or co-morbid psychopathologies, extensive life stress, or those who are non-compliant with medical follow-up, including a psychiatrist as part of the team is highly recommended.

It is also important to consider that psychotropic medications may have drug-drug interactions with medications used to treat IBD. For example, TNF-a decreases serotonin transporter function.(35) Psychotropic medications also require monitoring for potential side effects (e.g., suicidal ideation, akathesia). Finally, in children and adolescents, the long-term developmental consequences of these medications are not known. In conclusion, the firstline approach to psychological problems is psychosocial intervention by a mental health professional, and use of adjunctive psychotropic medication is best managed with the involvement of psychiatrist or behavioral pediatrician.

\section{Health-related Quality of Life}

\section{Overview}

The World Health Organization defines health as encompassing physical, mental, and social well-being, and health-related quality of life (HRQoL) has emerged as a construct which captures this multidimensional conceptualization(36). HRQoL is defined as one's subjective perception of the impact of a chronic medical condition (CMC) on physical, psychological and social well being(37). HRQoL is a key outcome to consider in the context of adaptation to CMCs, as evidenced by its recommended use as a patient-reported outcome in medication efficacy trials and its frequent use as a primary endpoint in clinical trials $(38,39)$. Multiple questionnaires exist to assess HRQoL, and these can be broadly grouped as either disease specific or generic measures(39). Disease specific measures assess the specific symptoms, functional status, and psychosocial functioning of individuals with a particular CMC and may be more sensitive to the unique challenges associated with a particular $\mathrm{CMC}$ and to small but clinically significant changes in functioning as a result of treatment(40). In contrast, generic measures of HRQoL tap domains of physical and psychosocial functioning that are relevant to both healthy and ill populations, and as such, are generally broader in their foci than are disease specific measures(39). HRQoL has been typically assessed in pediatric populations through self-report or via parent proxy report; however, it is recommended that parent proxy report be viewed as a supplement rather than a replacement for child report $(39,41)$.

In the context of pediatric IBD, HRQoL has been a relatively well-studied construct. In fact, researchers have developed a disease-specific measure of HRQoL: the IMPACT-III(42-44) and have established the validity other generic HRQoL measures such as the PedsQL 4.0 Generic Core Scales $(45,46)$ for this population. Understanding the HRQoL of youth with IBD is of relevance to clinicians given the physical and emotional demands associated with management of IBD. Symptoms of IBD such as weight loss, growth delay, fatigue, pain, and diarrhea have the potential to negatively impact HRQoL, as do nutritional modifications, medication regimens, and surgical interventions. HRQoL is a dynamic construct among youth with pediatric IBD, and HRQoL may improve over the course of the first year 
following diagnosis of $\operatorname{IBD}(47)$. However, limited research has focused on the natural trajectory of HRQoL in subpopulations of IBD patients other than recently diagnosed youth.

Data suggest that youth with IBD have lower HRQoL relative to healthy youth on generic HRQoL measures(12). Specifically, youth with IBD have lower HRQoL in total, psychosocial, and physical health domains based on both child and parent-proxy reports(12). Parent proxy-reports of HRQoL are suggestive of greater impairment than child self-reports of HRQoL(12). Additionally, although differences exist, generally the HRQoL of youth with IBD is quite high, and relatively few youth with IBD experience clinically significant impairments in HRQoL(12). Data suggest youth-reported HRQoL in pediatric IBD is comparable to that of youth with other chronic and acute conditions in overall HRQoL, as well as in physical health domains of HRQoL and general psychosocial health(12). However, youth with IBD may be at risk for lower HRQoL in the school functioning domain relative to youth with chronic and acute illnesses(12).

Several domains of risk factors for impaired HRQoL in pediatric IBD have been examined, including disease-related, demographic, psychosocial, and relationship factors. Regarding disease-related factors, higher disease activity is associated cross-sectionally with poorer child-reported HRQoL as assessed with both disease specific(48-52) and generic(47) measures, and with poorer parent-reported HRQoL as assessed with generic measures(47). Additionally, higher disease activity is associated with poorer functioning in both psychosocial and physical health domains $(47,53)$ and predicts poorer HRQoL one year after diagnosis(48). Even when accounting for disease activity, fatigue is an independent predictor of disease-specific HRQoL(53). The impact of type of treatment on HRQoL has also been examined. Conflicting evidence exists regarding the relationship between corticosteroid use and HRQoL in pediatric IBD, with one study finding lower HRQoL among youth prescribed steroids(54) and another study finding no relationship between steroid use and impaired HRQoL(48). Similarly, no differences in child-reported HRQoL have been documented between youth on aminosalicylates, immunomodulators, or anti-TNF a therapy(53). In one study, adolescents with Crohn's disesase reported poorer HRQoL than those with UC(51).

Demographic correlates of HRQoL have received relatively little attention in pediatric IBD. Older age was associated with lower disease-specific HRQoL in one study(48). Evidence for an association of sex with HRQoL is mixed, with one study suggesting poorer HRQoL among males(55) and another suggesting poorer HRQoL among females(50).

Regarding psychosocial correlates of HRQoL, the use of less adaptive coping strategies (e.g., avoidance) has been associated with poorer HRQoL, whereas higher confidence in one's ability to control future situations has been associated with better HRQoL in pediatric IBD samples(50). In the one study to date which has examined associations between depressive symptoms and HRQoL in adolescents with IBD, findings suggest negative associations between these constructs(54).

Relationship factors such as social support or family functioning rarely have been explored as influencing HRQoL in pediatric IBD, despite the well-established data suggesting these factors play a key role in promoting optimal adjustment in the context of chronic pediatric illness(56). Social support was positively associated with HRQoL in one study of youth with IBD(57). Similarly, family problems related to problem solving, communication, and general functioning have been cross-sectionally associated with disease-specific HRQoL among adolescents with $\operatorname{IBD}(51)$. 


\section{Recommendations for providers}

Several general recommendations for assessment of HRQoL among youth with IBD can be surmised from the existing literature. In general, we endorse broad screening of HRQoL among all youth with IBD at periodic intervals as a useful tool in screening for adjustment to condition and the functional impact of the condition. Specifically, we recommend that HRQoL be assessed each time there is a change in disease status (e.g., disease flare, hospital admission, etc.), a change in treatment regimen, or at regular intervals which coincide with routine clinical follow up. Although medical intervention is often successful in remediating disease-related symptoms, it can also produce adverse side effects, and changes to physical appearance which may influence HRQoL. Moreover, management of IBD and its symptoms has the potential to interfere with school and social functioning, and create additional stress, offering additional support for the importance of HRQoL assessment. To this end, we offer several suggestions for assessment of HRQoL. First, the use of developmentally appropriate, validated, and psychometrically sound measures is key in obtaining reliable data. Several such measures exist, including the PedsQL 4.0 Generic Core Scales (a generic HRQoL measure) $(45,46)$ and the IMPACT-III (a disease specific measure)(42-44). These measures may yield valuable data when used at key times in the IBD treatment process including near the time of diagnosis (as an index of baseline HRQoL) and at periodic intervals during the course of treatment including following initial remission of symptoms or at subsequent times of relapse or remission (as a means of assessing subjective impact of the disease and its treatment). Since most HRQoL instruments can be completed in less than 5 minutes, they are feasible for incorporation into clinical practice. Second, evidence suggests value in the assessment of both generic and disease-specific HRQoL. Third, it is recommended that HRQoL assessment focuses primarily on youth report, and that parent-proxy report viewed as a supplement to youth report except in situations in which youth are unable to reliably self-report (e.g., youth younger than 5 years, youth with significant cognitive or developmental delay; youth who are too ill to complete the measure). Fourth, the inclusion of patient-reported HRQoL as a primary endpoint in randomized clinical trials, efficacy studies, or quality improvement efforts should be continued. Doing so may yield information about functional impact of disease, which may not be adequately assessed by disease activity measures. It may also provide information about the desirable and undesirable effects of various intervention approaches on domains of functioning outside of those specifically influenced by disease processes(39).

When impairments in HRQoL are documented, providers may benefit from monitoring these closely to determine the extent to which these are situational-based decreases (i.e., due to a recent disease flare), or more reflective of a consistent pattern of impairment. For youth who evidence a pattern of impaired HRQoL across repeated assessments, then referral to a mental health professional such as a pediatric psychologist is recommended to identify strategies for enhancing physical and psychosocial functioning and improving subjective sense of well-being. At present, evidence-based intervention strategies to enhance HRQoL is limited in pediatric IBD. Among adults with IBD, self-management training has resulted in improved HRQoL in the short term, $(58,59)$ as have psychosocial intervention $(60,61)$; however, research is needed to document their efficacy in enhancing HRQoL in pediatric IBD populations.

\section{Social Functioning}

\section{Overview}

The symptoms and treatment of IBD can be conducive to social limitations, and problematic social functioning is a significant predictor of difficulties later in life. $(62,63)$ Thus, it is important to consider social functioning as part of psychosocial assessment. Social 
functioning encompasses several domains, including social skills, social behavior, and social adjustment.(64) Social skills are the abilities needed to behave competently in social settings, such as assertiveness and empathy. Social behavior refers to actual behaviors in social interactions, and social adjustment encompasses the quality of adolescent's relationships and the extent to which they attain socially desirable and developmentally appropriate goals. Social behavior and adjustment include peer acceptance and victimization, and participation in developmentally-appropriate social activities such as sports and romantic relationships. Most of the research in pediatric IBD has investigated the domains of social behavior and adjustment. In a meta-analysis of eight studies examining social behavior and adjustment, youth with IBD reported significantly worse social functioning than healthy children but similar functioning compared with children with other chronic illnesses.(12) Parents reported no significant differences when compared with healthy children, although children may be better informants about what is socially important to them than their parents. Rates of clinically significant social difficulty ranged from $2-22 \%$ in two studies. $(65,66)$ In one study investigating social skills, there was no significant difference between healthy children and those with IBD.(67)

A few studies have identified factors that put youth with IBD at increased risk for social difficulty. Boys with IBD have more social difficulty than girls with IBD or healthy children, including social problems that reach clinical significance. Onset of IBD during adolescence is also associated with worse social functioning.(66)

Although social functioning can be challenging for youth with IBD, no interventions have focused solely on this area. A few interventions focusing on other issues have briefly addressed social difficulty and may hold promise for the development of more comprehensive interventions. Szigethy and colleagues(21) conducted cognitive behavioral therapy aimed at improving depression symptoms in depressed adolescents with IBD. One of the individual therapy sessions addressed problem-solving for social situations and planning social activities. Social functioning improved after treatment ended. Szigethy and colleagues(23) also evaluated a support group for adolescent girls and their mothers. An hour of unstructured social time was followed by educational topics, including the social topic of dating and intimacy. The social subscale of a health-related quality of life measure improved after the 10-month series. Finally, attending an IBD camp was associated with improvement in social quality of life.(68) The findings from the support group and camp studies suggest that less-structured social opportunities with similar peers may be beneficial.

\section{Recommendations for Providers}

Social functioning should be monitored, and particular attention should be paid to boys and those diagnosed in adolescence. Patients and parents should be asked about any social withdrawal, interpersonal difficulty with peers, and difficulty participating in usual social or athletic activities. Since school is an important social arena for youth, school attendance should be monitored. If support groups are available for youth in the area, they may be a useful resource for providing social opportunities with other youth with IBD. The Crohn's and Colitis Foundation of America's (CCFA) Camp Oasis is another resource for these opportunities. Youth can also become involved in IBD-related activities such as CCFA's Take Steps walk. Several websites exist that may help increase social connectivity. For example, the CCFA-sponsored www.ucandcrohns.org website is a site for youth, and popular social networking websites have several different pages for IBD, including one that has the support of over 22,000 people. Social problem-solving can include ways to manage a social life while experiencing active symptoms. The www.ucandcrohns.org website offers many tips for handling social situations, and children can add their own tips to the site. Bathroom finder websites and cell phone applications also exist and can be useful for social 
problem-solving. If the social difficulty significantly affects a child's life and/or causes significant distress, a referral to a mental health professional is warranted.

\section{Family Functioning \\ Overview}

Pediatric IBD can also impact parents and siblings and be a source of increased stress among family members. This can disrupt overall family functioning and adversely impact the physical and psychosocial health of youth with IBD. Family functioning is thereby a key component to understanding the overall functioning of youth with IBD.

Research findings on family functioning in pediatric IBD have largely been mixed. Some have documented significantly greater family dysfunction among families of patients with IBD compared to healthy controls(69), while others report no differences relative to healthy comparisons(66). Although, on average, families report healthy levels of family functioning, many endorse clinically elevated family dysfunction with communication, family roles/ responsibilities, and the degree to which family members are involved in one another's lives(51). These findings may reflect the natural course of IBD (i.e., alternating periods of remission and flare-ups) and the consequent impact on family life. IBD demands may constrain families' ability to communicate effectively with one another, and family roles/ responsibilities may change to accommodate any symptoms due to disease flares (e.g., one caregiver stays with ill child in hospital, while other caregiver cares for healthy children and household tasks).

In fact, there is evidence that family dysfunction is related to more frequent bowel movements and greater pain/fatigue among youth with $\operatorname{IBD}(70)$. Family functioning may thus account for some of the variability in health status among youth with IBD, but little is known about the relationship between family functioning and the disease course of pediatric IBD, highlighting the need for further research.

The relationship between family functioning and psychosocial health in pediatric IBD also remains unclear. However, adaptive family relationships among other pediatric groups have been linked to positive psychological functioning and better health-related quality of life (HRQOL) $(71,72)$, while disruptions in family life have been related to poorer emotional and behavioral functioning(73). Research is thus needed to improve our understanding of the impact of family functioning on the psychosocial adjustment of youth with IBD. Given the pertinence of family functioning, family-focused interventions that target communication and problem-solving around disease management have shown great promise for improving health and psychosocial outcomes, particularly in the area of adherence $(74,75)$.

In the context of a child's chronic medical condition, the parent's own functioning can also play a key role in the child's psychological adjustment(76). In pediatric IBD, parents are found to exhibit heightened levels of emotional distress(77), and increased rates of depression(78). Poorer psychosocial functioning among mothers of adolescents with IBD has been linked to greater adolescent depressive symptoms and more negative IBD health outcomes(70). Moreover, worse psychosocial functioning among mothers of adolescents with IBD has been associated with greater IBD-related functional disability in daily activities (i.e., school, extracurricular activities)(69). Another study of adolescents with IBD showed that higher levels of parenting stress significantly predicted poorer youth HRQOL(51).

Parents of youth with IBD also report significantly lower perceived social support compared to parents of healthy children, despite feeling equally integrated in social networks(79). This 
suggests that while parents of youth with IBD have available social support networks, they may not derive adequate levels of support from them. Parents may consequently be missing out on this key protective factor, which has long been identified as facilitating parents' adjustment to caring for a child with chronic medical needs $(80,81)$.

Little is known about the functioning of siblings of youth with IBD. Siblings of youth with IBD may similarly be at risk of psychosocial difficulties. Some evidence suggests that siblings of youth with IBD are at greater risk of symptoms of anxiety and depression, compared to siblings of healthy children(82). Siblings may also experience difficulties adjusting to their ill sibling's disease. In fact, siblings of youth with IBD voice primary concerns with parents keeping information from them about their sibling's IBD, their ill sibling being bullied at school, and being fearful about their sibling's disease and treatment $(83)$. The management of pediatric IBD should thus consider the functioning of siblings.

\section{Recommendations for providers}

Overall, family functioning is a critical factor to consider when caring for young patients with IBD, including the functioning of patients, siblings, and parents alike. Providers can achieve this by asking families how they are coping with the IBD diagnosis and disease management tasks, and asking about the presence of any family stress and the availability of support networks. This may identify families in need of support services, as well as patients who may be at heightened risk of psychosocial difficulties. Families may further benefit from guidance about what they might expect from the point of diagnosis and forward (anticipatory guidance), particularly around coping with chronic illness demands (e.g., remaining in open communication with child's GI providers, seeking support from friends, using CCFA resources). Collaboration between pediatric providers and mental health professionals is thus crucial to ensure that families have access to support resources and their needs are appropriately met.

\section{School Functioning}

Overview

School functioning includes academic performance, school attendance, educational attainment, and psychosocial functioning in the school context. Much of what is known about school functioning in pediatric IBD is based on descriptive cross-sectional studies employing small samples or retrospective reports. Thus, our understanding of how school functioning in pediatric IBD is limited at present. Most youth with IBD perceive their condition has caused academic underachievement or adversely impacted their education(8486). However, objective data suggest similar levels of academic performance of youth with IBD compared to the general population, and similar or higher levels of educational attainment compared to healthy controls(87-89).

Some evidence for impairments in school attendance among youth with IBD exists. Youth with IBD report higher rates of school absences than comparison youth(90). In one study, youth with IBD missed an average of three months of school in the past year(84). In another, the mean estimate of lifetime school absences was 13 weeks, a rate that was significantly higher than that of a comparison sample(90). Although the magnitude of differences was not evaluated statistically, mean lifetime school absences of those with IBD were nearly two to three times that of individuals with other GI disorders. However, individuals with IBD did not significantly differ from control participants in percent of classes failed or in final educational level(89). 
Perceived impairments in school functioning domains of HRQoL have been reported by adolescents with IBD and their parents relative to healthy youth, youth with other chronic illnesses, and acutely ill youth(47). Finally, one recent study offers evidence for poorer college adjustment among those with IBD relative to healthy controls and suggests that youth with active disease may be at particular risk for poor outcomes(91).

Several factors may be associated with impaired school functioning in the context of pediatric IBD. First, disease-related processes or symptoms may directly influence neuropsychological functioning thereby influencing academic performance. For example, anemia or nutritional deficits may impair cognitive functioning in $\operatorname{IBD}(92,93)$ In addition, research suggests that adults with IBD display cognitive deficits that appear to be organic in nature(94) which are not explained by depressive symptoms, cognitive load, or medication effects $(95,96)$. The specific implications of such deficits for school functioning, however, have not yet been explored.

In addition, other disease symptoms such as fatigue or pain may influence school functioning via increasing the likelihood of school absences or concentration difficulties at school. Among youth with IBD, fatigue has been reported as an impediment to academic performance(85). Abdominal pain is a common symptom among youth with IBD, even those with no clinical disease activity(97); however, links between pain and school functioning have not been empirically examined. In addition, certain treatment regimens, such as corticosteroid use, may adversely impact school functioning via impairing cognitive functioning(15).

\section{Recommendations for providers}

Given the paucity of research on school functioning in pediatric IBD, our ability to make evidence-based recommendations is limited. At present, data suggest that youth with IBD may perceive their school functioning to be impaired; however objective data have not supported this. Nonetheless, a perceived impairment in school functioning may set the stage for the development of adjustment problems and may warrant clinical attention. Obtaining objective data on number of school absences, as well as school grades is likely to yield useful information for providers, and patients who report frequent absences may benefit from a referral to a mental health professional to address any possible school avoidance issues. In addition, given that youth with greater disease activity may be at risk for perceived impairments in school functioning, special attention to this subgroup may be of benefit. Since transitions to new schools will require families to inform a new set of school personnel about the child or adolescent's condition and obtain support from the school in any necessary educational modifications, we recommend that health care professionals provide anticipatory guidance to families at these times and monitor absence rates and academic performance after the transition. For children or adolescents who have ongoing academic performance difficulties, referral to a psychologist for a comprehensive evaluation of neuropsychological strengths and weaknesses may be of benefit in identifying strategies to optimize the youth's learning environment.

Finally, all children and adolescents with IBD would benefit from having a system in place to allow for necessary accommodations that may arise due to symptoms of IBD. Many school districts work with families to develop medical plans in conjunction with school nurses to address needs of youth with chronic medical conditions. An alternative arrangement is for a 504 plan to be implemented within the local public school district. A 504 plan is a legal document that is designed to assist students with special physical and/or emotional needs who are in regular classroom settings and require accommodations within the regular educational setting. It is distinct from an Individualized Education Plan (IEP) which provides for formal special education services. 504 plans are designed to ensure that 
youth with special needs receive appropriate accommodations within the school setting, and they provide a formal mechanism for ensuring educators are aware of the special needs of a given student. Youth with IBD benefit from accommodations including unrestricted bathroom access and extended time to complete school assignments during periods of absence related to disease symptoms. Encouraging parents to contact the school about establishing a medical plan or a 504 plan at the time of diagnosis is a key manner in which health care providers can encourage optimal school functioning. The process of initiating a 504 plan request must be done in writing to the child's local school system and should outline the specific accommodations that the parent is requesting. Once a formal 504 plan request has been submitted, the school will conduct an evaluation of the student, convene a meeting with the parents to discuss the findings, and formalize a written plan for accommodations.

\section{Conclusions}

Pediatric IBD affects many areas of psychosocial functioning. Youth with IBD are at increased risk for internalizing disorders (e.g., depression, anxiety), poor HRQoL, social problems, and difficulty with school-related functioning. Additionally, family dysfunction may be evident during disease flares, and both parents and siblings of a child with IBD often report distress. Many psychosocial factors are significantly related to disease activity, which suggests that assessing psychosocial problems is particularly important when the disease is active. Several interventions have empirical support or show promise for addressing these issues. If a child or family is experiencing significant distress in any area of psychosocial function and/or psychosocial problems are interfering significantly with life, referral to a mental health professional is warranted (see Table 2). Future directions include conducting large, prospective studies to provide further support for specific psychosocial difficulties, developing brief screeners that can be easily used in clinical practice, and developing additional interventions that are evaluated in this population, including prevention efforts.

\section{Acknowledgments}

Funding

This work was supported by a grant from Nationwide Children's Hospital and R01HD058317 (Mackner), Crohn's and Colitis Foundation of America Senior Research Award \#2838 (Greenley), NIMH 1R01 MH077770 and DP2 OD001210 (Szigethy), K23 DK079037, PHS Grant P30 DK 078392 (Hommel)

\section{References}

1. Birmaher B, Brent D, Bernet W, et al. Practice parameter for the assessment and treatment of children and adolescents with depressive disorders. J Am Acad Child Adolesc Psychiatry. 2007; 46(11):1503-26. [PubMed: 18049300]

2. Dulcan, D. Textbook of Child and Adolescent Psychiatry. Arlington, VA: American Psychiatric Publishing, Inc; 2010.

3. Burke P, Meyer V, Kocoshis S, et al. Depression and anxiety in pediatric inflammatory bowel disease and cystic fibrosis. J Am Acad Child Adolesc Psychiatry. 1989; 28(6):948-51. [PubMed: 2808268]

4. Szigethy E, Carpenter J, Baum E, et al. Case study: Longitudinal treatment of adolescents with depression and inflammatory bowel disease. J Amer Acad Child Adolesc Psychiatry. 2006; 45(4): 369-400.

5. Reigada LC, Fisher PH, Cutler C, et al. An innovative treatment approach for children with anxiety disorders and medically unexplained somatic complaints. Cogn Behav Pract. 2008; 15(2):140-7. [PubMed: 19484139] 
6. Szigethy E, McLafferty L, Goyal A. Inflammatory bowel disease. Child Adolesc Psychiatr Clin N Am. 2010; 19(2):301-18. ix. [PubMed: 20478501]

7. Engstrom I. Mental health and psychological functioning in children and adolescents with inflammatory bowel disease: a comparison with children having other chronic illnesses and with healthy children. J Child Psychol and Psychiatr. 1992; 33(3):563-82.

8. Szigethy E, Levy-Warren A, Whitton SB, et al. Depressive symptoms and inflammatory bowel disease in children and adolescents: A cross-sectional study. J Pediatr Gastroenterol Nutr. 2004; 39(4):395-403. [PubMed: 15448431]

9. APA. Diagnostic and Statistical Manual of Mental Disorders. 4. Washington, DC: Author; 1994.

10. Engstrom I, Lindquist BL. Inflammatory bowel disease in children and adolescents: a somatic and psychiatric investigation. Acta paediatr Scand. 1991; 80(6-7):640-7. [PubMed: 1867081]

11. Mackner LM, Crandall WV, Szigethy EM. Psychosocial functioning in pediatric inflammatory bowel disease. Inflamm Bowel Dis. 2006; 12(3):239-44. [PubMed: 16534426]

12. Greenley RN, Hommel KA, Nebel J, et al. A meta-analytic review of the psychosocial adjustment of youth with inflammatory bowel disease. J Pediatr Psychol. 2010; 35(8):857-69. [PubMed: 20123705]

13. Mittermaier C, Dejaco C, Waldhoer T, et al. Impact of depressive mood on relapse in patients with inflammatory bowel disease: a prospective 18-month follow-up study. Psychosom Med. 2004; 66(1):79-84. [PubMed: 14747641]

14. Zimmerman L, Srinath A, Nurko S, et al. Characterization of functional abdominal pain in pediatric crohn's disease. Gastro. 2010; 140(Supplement 1):S-510.

15. Mrakotsky C, Bousvaros A, Chriki L, et al. Impact of acute steroid treatment on memory, executive function, and mood in pediatric inflammatory bowel disease. J Pediatr Gastroenterol Nutr. 2005; 42:540-1.

16. Benhayon D, Binion D, Regueiro M, et al. Characterization of sleep in a pediatric population with inflammatory bowel disease and depression. Gastro. 2011; 140(Supplement 1):S-506-7.

17. Faure C, Giguere L. Functional gastrointestinal disorders and visceral hypersensitivity in children and adolescents suffering from Crohn's disease. Inflamm Bowel Dis. 2008; 14(11):1569-74. [PubMed: 18521915]

18. Coates MD, Johnson AC, Greenwood-Van Meerveld B, et al. Effects of serotonin transporter inhibition on gastrointestinal motility and colonic sensitivity in the mouse. Neurogastroenterol Motil. 2006; 18(6):464-71. [PubMed: 16700726]

19. Wolf AM, Wolf D, Rumpold H, et al. Overexpression of indoleamine 2,3-dioxygenase in human inflammatory bowel disease. Clin Immunol. 2004; 113(1):47-55. [PubMed: 15380529]

20. Compton SN, March JS, Brent D, et al. Cognitive-behavioral psychotherapy for anxiety and depressive disorders in children and adolescents: an evidence-based medicine review. J Am Acad Child Adolesc Psychiatry. 2004; 43(8):930-59. [PubMed: 15266189]

21. Szigethy E, Whitton SW, Levy-Warren A, et al. Cognitive-behavioral therapy for depression in adolescents with inflammatory bowel disease: a pilot study. J Am Acad Child Adolesc Psychiatry. 2004; 43(12):1469-77. [PubMed: 15564816]

22. Szigethy E, Kenney E, Carpenter J, et al. Cognitive-behavioral therapy for adolescents with inflammatory bowel disease and subsyndromal depression. J Am Acad Child Adolesc Psychiatry. 2007; 46(10):1290-8. [PubMed: 17885570]

23. Szigethy E, Hardy D, Craig AE, et al. Girls connect: effects of a support group for teenage girls with inflammatory bowel disease and their mothers. Inflamm Bowel Dis. 2009; 15(8):1127-8. [PubMed: 18972566]

24. Mufson L, Weissman MM, Moreau D, et al. Efficacy of interpersonal psychotherapy for depressed adolescents. Arch Gen Psychiatry. 1999; 56(6):573-9. [PubMed: 10359475]

25. Shaoul R, Sukhotnik I, Mogilner J. Hypnosis as an adjuvant treatment for children with inflammatory bowel disease. J Dev Behav Pediatr. 2009; 30(3):268. [PubMed: 19525722]

26. Emslie GJ, Rush AJ, Weinberg WAK, et al. A double-blind, randomized, placebo-controlled trial of fluoxetine in children and adolescents with depression. Arch Gen Psychiatry. 1997; 54(11): 1031-7. [PubMed: 9366660] 
27. Emslie GJ, Kennard BD, Mayes TL, et al. Fluoxetine versus placebo in preventing relapse of major depression in children and adolescents. Am J Psychiatry. 2008; 165(4):459-67. [PubMed: 18281410]

28. Wagner KD, Ambrosini P, Rynn M, et al. Efficacy of sertraline in the treatment of children and adolescents with major depressive disorder: two randomized controlled trials. JAMA. 2003; 290(8):1033-41. [PubMed: 12941675]

29. March J, Silva S, Petrycki S, et al. Fluoxetine, cognitive-behavioral therapy, and their combination for adolescents with depression: Treatment for Adolescents With Depression Study (TADS) randomized controlled trial. JAMA. 2004; 292(7):807-20. [PubMed: 15315995]

30. Walkup JT, Albano AM, Piacentini J, et al. Cognitive behavioral therapy, sertraline, or a combination in childhood anxiety. N Engl J Med. 2008; 359(26):2753-66. [PubMed: 18974308]

31. Ryan ND. Psychoneuroendocrinology of children and adolescents. Psychiatr Clin North Am. 1998; 21(2):435-41. [PubMed: 9670235]

32. March JS, Entusah AR, Rynn M, et al. A Randomized controlled trial of venlafaxine ER versus placebo in pediatric social anxiety disorder. Biol Psychiatry. 2007; 62(10):1149-54. [PubMed: 17553467]

33. Campo JV, Perel J, Lucas A, et al. Citalopram treatment of pediatric recurrent abdominal pain and comorbid internalizing disorders: an exploratory study. J Am Acad Child Adolesc Psychiatry. 2004; 43(10):1234-42. [PubMed: 15381890]

34. Kovacs, M. Children's Depression Inventory Manual. North Tonawanda, NY: Multi-Health Systems, Inc; 1992.

35. Foley KF, Pantano C, Ciolino A, et al. IFN-gamma and TNF-alpha decrease serotonin transporter function and expression in Caco2 cells. Am J Physiol Gastrointest Liver Physiol. 2007; 292(3):G779-84. [PubMed: 17170025]

36. Drotar, DLR.; Plaermo, TM., et al. Clinical applications of health related quality of life assessment for children and adolescents. In: Drotar, D., editor. Measuring Health-related Quality of Life in Children and Adolescents: Implications for Research and Practice. Mahwah, NJ: Lawrence Erlbaum; 1998. p. 329-39.

37. Eiser, C. Social support in chronically sick children and their families. In: Nestman, F.; Hurrelmann, K., editors. Social Networks and Social Support in Childhood and Adolescence. New York: Walter de Gruyter; 1994. p. 347-59.

38. Quittner, A.; Davis, M.; Modi, A. Health-related quality of life in pediatric populations. In: MR, editor. Handbook of Pediatric Psychology. New York: Guilford; 2003. p. 696-709.

39. Palermo TM, Long AC, Lewandowski AS, et al. Evidence-based assessment of health-related quality of life and functional impairment in pediatric psychology. J Pediatr Psychol. 2008; 33(9): 983-96. discussion 97-8. [PubMed: 18430762]

40. Matza LS, Swensen AR, Flood EM, et al. Assessment of health-related quality of life in children: a review of conceptual, methodological, and regulatory issues. Value Health. 2004; 7(1):79-92. [PubMed: 14720133]

41. Riley AW. Evidence that school-age children can self-report on their health. Ambul Pediatr. 2004; 4(4 Suppl):371-6. [PubMed: 15264962]

42. Griffiths A, Nicholas D, Smith C, et al. Development of a quality-of-life index for pediatric inflammatory bowel disease. Inflamm Bowel Dis. 2006; 12:684-91. [PubMed: 16917222]

43. Otley A, Smith C, Nicholas D, et al. The IMPACT questionnaire: A valid measure of healthrelated quality of life in pediatric inflammatory bowel disease. J Pediatr Gastroenterol Nutr. 2002; 35(4):557-63. [PubMed: 12394384]

44. Otley, A. Measurement of quality of life in pediatric inflammatory bowel disease. In: Mamula, P.; Baldassano, R.; Markowitz, J., editors. Pediatric Inflammatory Bowel Disease. New York: Springer; 2008. p. 565-76.

45. Varni JW, Seid M, Kurtin PS. PedsQL 4.0: reliability and validity of the Pediatric Quality of Life Inventory version 4.0 generic core scales in healthy and patient populations. Med Care. 2001; 39(8):800-12. [PubMed: 11468499] 
46. Varni JW, Burwinkle TM, Seid M, et al. The PedsQL 4.0 as a pediatric population health measure: feasibility, reliability, and validity. Ambulatory Pediatrics. 2003; 3(6):329-41. [PubMed: 14616041]

47. Kunz JH, Hommel KA, Greenley RN. Health-related quality of life of youth with inflammatory bowel disease: a comparison with published data using the PedsQL 4.0 generic core scales. Inflamm Bowel Dis. 2010; 16(6):939-46. [PubMed: 19998462]

48. Otley AR, Griffiths AM, Hale S, et al. Health-related quality of life in the first year after a diagnosis of pediatric inflammatory bowel disease. Inflamm Bowel Dis. 2006; 12(8):684-91. [PubMed: 16917222]

49. Loonen HJ, Grootenhuis MA, Last BF, et al. Quality of life in paediatric inflammatory bowel disease measured by a generic and a disease-specific questionnaire. Acta Paediatr. 2002; 91(3): 348-54. [PubMed: 12022311]

50. van der Zaag-Loonen HJ, Grootenhuis MA, Last BF, et al. Coping strategies and quality of life of adolescents with inflammatory bowel disease. Qual Life Res. 2004; 13(5):1011-9. [PubMed: 15233514]

51. Herzer M, Denson LA, Baldassano RN, et al. Family functioning and health-related quality of life in adolescents with pediatric inflammatory bowel disease. Eur J Gastroenterol Hepatol. 2011; 23(1):95-100. [PubMed: 21079514]

52. Perrin JM, Kuhlthau K, Chughtai A, et al. Measuring quality of life in pediatric patients with inflammatory bowel disease: psychometric and clinical characteristics. J Pediatr Gastroenterol Nutr. 2008; 46(2):164-71. [PubMed: 18223375]

53. Marcus SB, Strople JA, Neighbors K, et al. Fatigue and health-related quality of life in pediatric inflammatory bowel disease. Clin Gastroenterol Hepatol. 2009; 7(5):554-61. [PubMed: 19418604]

54. Cunningham C, Drotar D, Palermo T, et al. Health-related quality of life in children and adolescents with inflammatory bowel disease. Child Healthcare. 2007; 36(1):29-43.

55. De Boer M, Grootenhuis M, Derkx B, et al. Health-related quality of life and psychosocial functioning of adolescents with inflammatory bowel disease. Inflamm Bowel Dis. 2005; 11(4): 400-6. [PubMed: 15803032]

56. Drotar D. Relating parent and family functioning to the psychological adjustment of children with chronic health conditions: what have we learned? What do we need to know? J Pediatr Psychol. 1997; 22(2):149-65. [PubMed: 9114640]

57. MacPhee M, Hoffenberg EJ, Feranchak A. Quality-of-life factors in adolescent inflammatory bowel disease. Inflamm Bowel Dis. 1998; 4(1):6-11. [PubMed: 9552222]

58. Kennedy A, Nelson E, Reeves D, et al. A randomised controlled trial to assess the effectiveness and cost of a patient orientated self management approach to chronic inflammatory bowel disease. Gut. 2004; 53:1639-45. [PubMed: 15479685]

59. Garcia-Vega E, Fernandez-Rodriguez C. A stress management programme for Crohn's disease. Behav Res Ther. 2004; 42(4):367-83. [PubMed: 14998732]

60. von Wietersheim J, Kessler H. Psychotherapy with chronic inflammatory bowel disease patients: a review. Inflamm Bowel Dis. 2006; 12(12):1175-84. [PubMed: 17119392]

61. Jantschek G, Zeitz M, Pritsch M, et al. Effect of psychotherapy on the course of Crohn's disease. Results of the German prospective multicenter psychotherapy treatment study on Crohn's disease. German Study Group on Psychosocial Intervention in Crohn's Disease. Scand J Gastroenterol. 1998; 33(12):1289-96. [PubMed: 9930393]

62. Gest SD, Sesma A Jr, Masten AS, et al. Childhood peer reputation as a predictor of competence and symptoms 10 years later. J Abnorm Child Psychol. 2006; 34(4):509-26. [PubMed: 16850285]

63. Parker JG, Asher SR. Peer relations and later personal adjustment: are low-accepted children at risk? Psychol Bull. 1987; 102(3):357-89. [PubMed: 3317467]

64. Cavell TA. Social adjustment, social performance, and social skills: A tri-component model of social competence. J Clin Child Psychol. 1990; 19(2):111-22.

65. Mackner LM, Crandall WV. Long-term psychosocial outcomes reported by children and adolescents with inflammatory bowel disease. Am J Gastroenterol. 2005; 100(6):1386-92. [PubMed: 15929775] 
66. Mackner LM, Crandall WV. Brief report: Psychosocial adjustment in adolescents with inflammatory bowel disease. J Pediatr Psychol. 2006; 31(3):281-5. [PubMed: 15802606]

67. Mackner LM, Vannatta K, Crandall WV. Gender Differences in the Social Functioning of Adolescents with Inflammatory Bowel Disease. J Clin Psychol Med Settings. 2012

68. Shepanski MA, Hurd LB, Culton K, et al. Health-related quality of life improves in children and adolescents with Inflammatory Bowel Disease after attending a camp sponsored by the Crohn's and Colitis Foundation of America. Inflamm Bowel Dis. 2005; 11(2):164-70. [PubMed: 15677910]

69. Engstrom I. Inflammatory bowel disease in children and adolescents: Mental health and family functioning. J Pediatr Gastroenterol Nutr. 1999; 28(4):S28-S33. [PubMed: 10204521]

70. Tojek TM, Lumley MA, Corlis M, et al. Maternal correlates of health status in adolescents with inflammatory bowel disease. J Psychosom Res. 2002; 52(3):173-9. [PubMed: 11897236]

71. Grey M, Boland EA, Yu C, et al. Personal and family factors associated with quality of life in adolescents with diabetes. Diabetes Care. 1998; 21(6):909-14. [PubMed: 9614606]

72. Hanson CL, De Guire MJ, Schinkel AM, et al. Comparing social learning and family systems correlates of adaptation in youths with IDDM. J Pediatr Psychol. 1992; 17(5):555-72. [PubMed: 1432481]

73. Whittemore R, Kanner S, Singleton S, et al. Correlates of depressive symptoms in adolescents with type 1 diabetes. Pediatr Diabetes. 2002; 3(3):135-43. [PubMed: 15016153]

74. Anderson BJ, Brackett J, Ho J, et al. An office-based intervention to maintain parent-adolescent teamwork in diabetes management. Impact on parent involvement, family conflict, and subsequent glycemic control. Diabetes Care. 1999; 22(5):713-21. [PubMed: 10332671]

75. Wysocki T, Harris MA, Buckloh LM, et al. Randomized, controlled trial of Behavioral Family Systems Therapy for Diabetes: maintenance and generalization of effects on parent-adolescent communication. Behav Ther. 2008; 39(1):33-46. [PubMed: 18328868]

76. Thompson RJ, Gustafson KE, Hamlett KW, et al. Psychological adjustment of children with cystic fibrosis: the role of child cognitive processes and maternal adjustment. J Pediatr Psychol. 1992; 17(6):741-55. [PubMed: 1484336]

77. Engstrom I. Parental distress and social interaction in families with children with inflammatory bowel disease. J Am Acad Child Adolesc Psychiatry. 1991; 30(6):904-12. [PubMed: 1757439]

78. Burke PM, Kocoshis S, Neigut D, et al. Maternal psychiatric disorders in pediatric inflammatory bowel disease and cystic fibrosis. Child Psychiatry Hum Dev. 1994; 25(1):45-52. [PubMed: 7805435]

79. Engstrom I. Parental distress and social interaction in families with children with inflammatory bowel disease. J Am Acad Child Adolesc Psychiatry. 1991; 30(6):904-12. [PubMed: 1757439]

80. Speechley KN, Noh S. Surviving childhood cancer, social support, and parents' psychological adjustment. J Pediatr Psychol. 1992; 17(1):15-31. [PubMed: 1545319]

81. Hoekstra-Weebers JE, Jaspers JP, Kamps WA, et al. Psychological adaptation and social support of parents of pediatric cancer patients: a prospective longitudinal study. J Pediatr Psychol. 2001; 26(4):225-35. [PubMed: 11329482]

82. Engstrom I. Psychological problems in siblings of children and adolescents with inflammatory bowel disease. Eur Child Adol Psy. 1992; (1):24-33.

83. Akobeng AK, Miller V, Firth D, et al. Quality of life of parents and siblings of children with inflammatory bowel disease. J Pediatr Gastroenterol Nutr. 1999; 28(4):S40-2. [PubMed: 10204524]

84. Moody G, Eaden JA, Mayberry JF. Social implications of childhood Crohn's disease. J Pediatr Gastroentrol Nutr. 1999; 28(4):S43-S5.

85. Rabbett H, Elbadri A, Thwaites R, et al. Quality of life in children with Crohn's disease. J Pediatr Gastroenterol Nutr. 1996; 23(5):S28-S33.

86. Ferguson A, Sedgwick DM, Drummond J. Morbidity of juvenile onset inflammatory bowel disease: Effects on education and employment in early adult life. Gut. 1994; 35(5):665-8. [PubMed: 8200562]

87. Bernstein CN, Kraut A, Blanchard JF, et al. The relationship between inflammatory bowel disease and socioeconomic variables. Am J Gastroenterol. 2001; 96(7):2117-25. [PubMed: 11467642] 
88. Longobardi T, Jacobs $\mathrm{P}$, Wu L, et al. Work losses related to inflammatory bowel disease in Canada: results from a National Population Health Survey. Am J Gastroenterol. 2003; 98(4):8449. [PubMed: 12738466]

89. Marri SR, Buchman AL. The education and employment status of patients with inflammatory bowel diseases. Inflamm Bowel Dis. 2005; 11(2):171-7. [PubMed: 15677911]

90. Calsbeek H, Rijken M, Bekkers MJ, et al. Social position of adolescents with chronic digestive disorders. Eur J Gastroenterol Hepatol. 2002; 14(5):543-9. [PubMed: 11984153]

91. Adler J, Raju S, Beveridge AS, et al. College adjustment in University of Michigan students with Crohn's and colitis. Inflamm Bowel Dis. 2008; 14(9):1281-6. [PubMed: 18512247]

92. Thayu M, Mamula P. Treatment of iron deficiency anemia in pediatric inflammatory bowel disease. Curr Treat Options Gastroenterol. 2005; 8(5):411-7. [PubMed: 16162307]

93. Bryan J, Osendarp S, Hughes D, et al. Nutrients for cognitive development in school-aged children. Nutr Rev. 2004; 62(8):295-306. [PubMed: 15478684]

94. Hollerbach S, Kullman F, Geissler A, et al. Impairment of short term memory functioning and morphological brain abnormalities in inflammatory bowel disease. Gastroenterol. 2000; (118): 1723.

95. Attree EA, Dancey CP, Keeling D, et al. Cognitive function in people with chronic illness: inflammatory bowel disease and irritable bowel syndrome. Appl Neuropsychol. 2003; 10(2):96104. [PubMed: 12788684]

96. Dancey CP, Attree EA, Stuart G, et al. Words fail me: the verbal IQ deficit in inflammatory bowel disease and irritable bowel syndrome. Inflamm Bowel Dis. 2009; 15(6):852-7. [PubMed: 19130620]

97. Greenley, R.; Kunz, H.; Schurmann, J., et al. Unpublished manuscript. 2011. Cross-sectional and longitudinal associations of abdominal pain with quality of life in youth with inflammatory bowel disease. 
Table 1

Summary of Recommendations for Providers

\begin{tabular}{|c|c|}
\hline Psychosocial Area & Recommendations \\
\hline General/All areas & $\begin{array}{l}\text { Differentiate short-term, situational distress (e.g., diagnosis or flare related) from extended period of } \\
\text { impaired functioning } \\
\text { - If the difficulty significantly affects a child's life and/or causes significant distress, refer to a mental health } \\
\text { professional with training in understanding the unique impact of pediatric chronic illness (e.g., psychologist, } \\
\text { therapist, social worker, counselor) }\end{array}$ \\
\hline Psychopathology & $\begin{array}{l}\text { - Use screening tools (e.g., MESSAGE) or QOL proxies (e.g., well-being item on PCDAI) } \\
\text { - } \\
\text { - } \\
\text { - Little empitive behavioral therapy (CBT) has the most empirical support for treating anxiety, depression } \\
\text { - } \\
\text { - } \\
\text { Frequent follow-up visits recommended } \\
\text { Include a psychiatrist if patient: } \\
\text { - Fails a class of antidepressant } \\
\text { - } \quad \text { Has severe or co-morbid psychopathologies or extensive life stress } \\
\text { - } \quad \text { Are non-compliant with medical follow-up }\end{array}$ \\
\hline HRQoL & $\begin{array}{l}\text { - Assess HRQoL with changes in disease status or treatment regimen, or at regular intervals coinciding with } \\
\text { routine clinical follow up } \\
\text { Assess generic and disease-specific HRQoL } \\
-\quad \text { PedsQL Generic Core Scales }{ }^{a} \\
-\quad \text { IMPACT-III } \\
\text { - } \\
\text { Focus primarily on youth report except when youth are unable to reliably self-report ( }<5 \text { years, significant } \\
\text { developmental delay, too ill to complete) } \\
\text { - Continue using HRQoL as primary endpoint in RCT's and efficacy and quality improvement studies } \\
\text { - Self-management training and psychosocial interventions improve HRQoL in the short term }\end{array}$ \\
\hline Social & $\begin{array}{l}\text { - Assess multiple areas: Social withdrawal, interpersonal difficulty with peers, difficulty participating in social } \\
\text { or athletic activities, school attendance } \\
\quad-\quad \text { Especially patients diagnosed in adolescence and boys } \\
\text { - CBT may improve social functioning; support groups and IBD camp may improve short-term social } \\
\text { functioning } \\
\text { - IBD-related activities and websites and bathroom finder websites and phone applications may be helpful }\end{array}$ \\
\hline Family & $\begin{array}{l}\text { - Assess family coping with diagnosis and disease management, family stress, availability of support networks } \\
\text { - Anticipatory guidance may be helpful, particularly regarding family coping with chronic illness demands }\end{array}$ \\
\hline School & $\begin{array}{l}\text { - Since a discrepancy between perceived and actual functioning may exist, obtain objective data on school } \\
\text { functioning if concerns are reported } \\
-\quad \text { Especially youth with worse disease activity } \\
\text { - Providing anticipatory guidance to families during school transitions and monitoring absences and academic } \\
\text { performance after the transition may be helpful } \\
\text { - A } 504 \text { plan for "Other Health Impairment" may be helpful } \\
\text { - Unrestricted bathroom access } \\
\text { - Accommodations for absences }\end{array}$ \\
\hline
\end{tabular}

${ }^{a}$ Available from http://www.pedsql.org

J Pediatr Gastroenterol Nutr. Author manuscript; available in PMC 2014 April 01. 
$b_{\text {By request of the authors (Otley et al;43) }}$ 
Table 2

MESSAGE acronym for depression screening

\begin{tabular}{|c|c|}
\hline M & Mood (depressed or irritable) and Motor (hyper or hypo) \\
\hline E & Energy (fatigue) \\
\hline S & Sleep (insomnia or hypersomnia) \\
\hline S & Suicide and Self Esteem \\
\hline A & Anhedonia (lack of pleasure) \\
\hline G & Guilt \\
\hline E & Eating (change in appetite) \\
\hline
\end{tabular}

Courtesy of Eva Szigethy, MD, PhD 